\title{
Hyponatraemic rhabdomyolysis in Addison's disease
}

\author{
J.J. Egan, A.J. Davies and M.K. Jones \\ Department of Medicine, Singleton Hospital, Swansea $S A 28 Q A, U K$
}

Summary: This case describes a novel association of rhabdomyolysis with severe normovolaemic hyponatraemia resulting from previously unrecognized Addison's disease in a 63 year old female.

\section{Introduction}

Rhabdomyolysis has rarely been reported in association with hyponatraemia and, in those patients described, hyponatraemia resulted from water intoxication. We describe a patient with rhabdomyolysis associated with severe Addisonian hyponatraemia. The mechanism of muscle breakdown may be the failure of the cellular adaptive mechanisms required in the presence of extracellular fluid hypoosmolality.

\section{Case report}

A 63 year old retired school teacher presented with an 11 hour history of confusion. She was accompanied by her cohabitant sister who had been with her throughout the period of her illness. On the day prior to admission she had noticed aches and pains in her back and limbs, and over the preceding 2 weeks she had complained of anorexia, lassitude and general malaise. There was no history of vomiting or seizures, and an aunt was known to have pernicious anaemia.

On examination she was thin, pigmented and disorientated. Skin turgor was normal and there was no peripheral oedema. Supine systolic blood pressure was $120 \mathrm{mmHg}$ with no postural drop. Initial investigations revealed a serum sodium of $97 \mathrm{mmol} / 1$ (135-145), potassium $5.8 \mathrm{mmol} / \mathrm{l}$ (3.5-5.3), urea $4.7 \mathrm{mmol} / 1$ (2.5-7.5), creatinine $50 \mu \mathrm{mol} / \mathrm{l}(20-95)$ and plasma glucose of $6.3 \mathrm{mmol} / \mathrm{l}$. Serum creatine kinase (CK) was $21,490 \mathrm{U} / 1$ (normal < 170) but no urinary myoglobin was detected (Labstix SG negative) (Beyer diagnostics). Serum-corrected calcium was $2.25 \mathrm{mmol} / \mathrm{l}(2.10-2.65)$, phosphate $1.3 \mathrm{mmol} / \mathrm{l}$ $(0.7-1.40)$, plasma osmolality was $216 \mathrm{mosmol} / \mathrm{kg}$ (286-295), urine osmolality $731 \mathrm{mosmol} / \mathrm{kg}$ and

Correspondence: J. Egan, M.R.C.P., North West Lung Centre, Wythenshawe Hospital, Southmoor Road, Manchester M23 9LT, UK.

Accepted: 24 March 1994

urinary sodium $93 \mathrm{mmol} / \mathrm{l}$. On admission the random plasma cortisol was $502 \mathrm{mmol} / 1$ and ACTH was $405 \mathrm{ng} / \mathrm{l}(40-80)$. Fasting cholesterol was ${ }_{0}^{\circ}$ $5.4 \mathrm{mmol} / \mathrm{l}$ (normal $<6.5 \mathrm{mmol} / \mathrm{l}$ ) and fasting trig- $\omega_{0}^{\circ}$ lyceride was $1.9 \mathrm{mmol} / 1$ (normal $<2.1 \mathrm{mmol} / 1$ ). $\circ$ Free thyroxine (T4) was $14 \mathrm{pmol} / 1$ (8.8-23.2), thyroid stimulating hormone (TSH) $3.2 \mathrm{mIU} / \mathrm{l}_{Z}$ $(0.5-5.5)$. The postero-anterior chest $\mathrm{X}$-ray? showed a small cardiac silhouette.

Subsequent investigations confirmed a diagnosis of primary adrenal failure due to autoimmuge disease. Following an intramuscular injection $9 \mathrm{f}$ depot tetracosactrin $(1 \mathrm{mg})$ given at 0900 hours 3 day 6 after transfer from hydrocortisone to de amethasone therapy $0.5 \mathrm{mg}$ twice daily, serum cortisol levels at $0,6,8,24$ and 48 hours were less than $170 \mathrm{mmol} / \mathrm{l}$. Adrenal cortex autoantibody was strongly positive. The recumbent and ambulant renin concentrations were $25.2(1.2-2.4) \stackrel{\varrho}{\rightarrow}$ and $40.8(3-4.3) \mathrm{pmol} / \mathrm{hour} / \mathrm{ml}$, respectively, while⿳亠丷厂 the recumbent and ambulant aldosterone concentrations were inappropriately normal.at $129 \mathrm{pmol} /$ 年 $(100-300)$ and $196(100-300)$ pmol/l, respectively.

On admission the patient was given an in- $\frac{0}{3}$ travenous infusion of normal saline one litre 8 hourly and hydrocortisone $200 \mathrm{mg}$ as a bolus 3 . followed by $100 \mathrm{mg}$ 6-hourly. The aim of therapy was to increase the serum sodium at a rate of $₹$ $0.5 \mathrm{mmol}-2 \mathrm{mmol} /$ hour (Figure 1). The rise in serum sodium over the 72 hours following admission was accompanied by a sustained clinical and $\overrightarrow{0}$ biochemical improvement. Serum CK fell towards the normal range over a period of 96 hours (Figure $N$ 1). The patient was discharged from hospital $10 \mathrm{~N}$ days following admission and is now well on conventional hydrocortisone and fludrocortisone ${ }_{\sigma}^{\omega}$ therapy.

\section{Discussion}

Rhabdomyolysis has been described in association $\frac{}{\mathbb{1}}$ with numerous conditions ${ }^{1}$ but has only rarely been $\frac{?}{\mathbb{D}}$ 


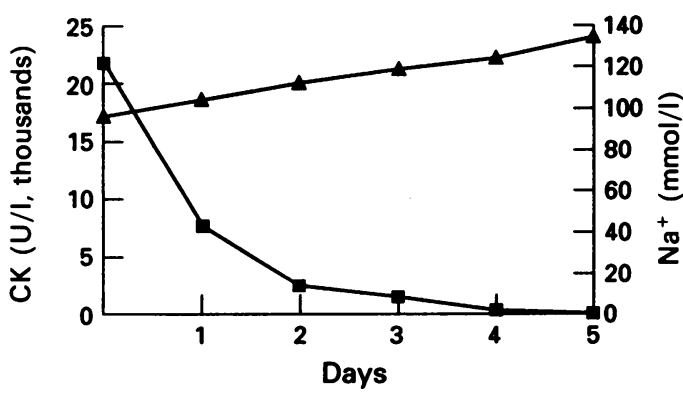

Figure 1 The changes in serum sodium ( $\Delta)$ and $C K(\square)$ following admission with the administration of intravenous hydrocortisone and normal saline.

reported in association with hyponatraemia. In each of the four cases previously described, the underlying cause of the hyponatraemia was water intoxication. We describe the first recorded case of rhabdomyolysis associated with Addisonian hyponatraemia.

The mechanism of rhabdomyolysis in hyponatraemia is unclear. Convulsions as a result of hyponatraemia can cause muscle damage and a subsequent rise in creatine phosphokinase. Two of the patients previously described had psychiatric disease requiring treatment with psychotropic agents, ${ }^{2,3}$ and one of these patients had dystonic movements and was combative. A third patient had a grand mal convulsion. ${ }^{4}$ Excess fluid ingestion was common to all four cases. ${ }^{2-5}$ There was no clinical evidence to suggest that our patient had suffered a convulsion.

It is suggested in the setting of hyponatraemia that, as the extracellular fluid osmolality falls, water diffuses across the cell membrane resulting in cellular oedema. The cell then adapts by extrusion of cellular potassium. ${ }^{6,7}$ Cell lysis (rhabdomyolysis) may result from cellular oedema caused by the ultimate failure of such an adaptive mechanism.

Our case highlights the inaccuracy of clinical bedside assessment of a presumed normovolaemic state. Although clinically normovolaemic, the patient was salt and water depleted. The apparent clinical normovolaemic state may be explained by either impaired renal free water excretion or excessive free water intake, both of which themselves

\section{References}

1. Gabow, P.A., Kaehney, W.D. \& Kelleher, S.P. The spectrum of rhabdomyolysis. Medicine 1982, 61: 141-152.

2. Adler, S. Hyponatraemia and rhabdomyolysis: a possible relationship. South Med J 1980, 73: 511-512.

3. Mor, F., Mor-Snir, I. \& Wysenbeek, A.J. Rhabdomyolysis in self induced water intoxication. $J$ Nerv Ment Dis 1987, 175: $742-743$. may have contributed to the severity of the hyponatraemia. Indeed this patient gave no history of vomiting. The degree of hyponatraemia described here, is most unusual in Addison's disease. Despite the presence of hypo-osmolar normovolaemic hyponatraemia, a diagnosis of the syndrome of inappropriate anti-diuretic hormone secretion cannot apply as Addison's disease by definition must be excluded. ${ }^{8}$ The diagnosis of adrenal insufficiency in a hyponatraemic patient even in the presence of clinical normovolaemia therefore must always be considered.

The clinical state of normovolaemia in our patient may be further explained by the presence of some adrenal reserve as suggested by the initial random cortisol level of $502 \mathrm{mmol} / \mathrm{l}$ and the normal aldosterone level. It is apparent though that the interpretation of a random plasma cortisol in an ill patient is difficult and the sequence of events seen here reinforces the importance of using a formal adrenal stimulation test in achieving an accurate diagnosis of primary adrenal insufficiency. ${ }^{9}$

It is worth noting the absence of urinary myoglobinuria in the case described. This may represent a low baseline myoglobin content in the deconditioned muscle of this middle-aged female, which in the presence of rhabdomyolysis failed to achieve an excess of the 'renal threshold' for myoglobin. ${ }^{10}$ The absence of myoglubinuria does not preclude rhabdomyolsis, rather it emphasizes that rhabdomyolysis is a subtle process only becoming apparent in many conditions through the detection of an elevated CK. ${ }^{10}$ Thus one might speculate that rhabdomyolysis may occur with greater frequency than previously recognized in Addison's disease, particularly as myalgia is a common symptom in cortisol-deficient patients and diverse muscle-related symptoms can be the presenting feature of Addison's disease. ${ }^{11}$

This case documents a novel primary aetiology in association with hyponatraemic rhabdomyolysis. It emphasizes the importance of considering primary adrenal failure as a cause of clinical normovolaemic hyponatraemia and demonstrates how a random cortisol can potentially be misleading in an ill patient, confirming the importance of using a long-acting stimulation test in achieving a diagnosis of Addison's disease.
4. Sidi, Y., Gassner, S., Snadbank, U., Keren, G. \& Pinkhas, J. Water intoxication, hyperpyrexia and rhabdmyolysis in a patient with psychogenic polydipsia. NY State J Med 1984, 84: 462-464.

5. Browne, P.M. Rhabdomyolysis and myoglobinuria associated with acute water intoxication. West Med J 1979. 130: 459-461. 
6. Verbalis, J.G. \& Drutarosky, M.D. Adaption to chronic hypoosmolality in rats. Kidney Int 1988, 34: 351-360.

7. Verbalis, J.G. Hyponatraemia. Ballières Clin Endrocrinol Metab 1989, 3 (2): 499-530.

8. Bartter, F.C., Schwartz, W.B. The syndrome of inappropriate secretion of antidiuretic hormone. Am J Med 1967, 42: 790-806.

9. Trump, D., Toms, G.C., Monson, J.P. \& Bradbury, W.H. Diagnosis of adrenal insufficiency. Br Med J 1989, 298: 670.
10. Knochel, J.P. Rhabdomyolysis and myoglobinuria. In: Suki,,$\frac{a}{\mathbb{Q}}$ W.N. \& Eknoyan, G. (eds) The Kidney in Systemic Disease, 2nd edn. John Wiley, New York, 1981, pp. 263-284.

11. Shapiro, M.S., Trebich, C., Shilo, L. \& Shenkman, L. Myalgias and muscle contractures as the presenting signs of Addison's disease. Postgrad Med J 1988, 64: 222-223. 